\title{
The Introduction of Management Control in the Legislative Assembly of the Emilia-Romagna Region
}

\author{
Pietra Paola Amata ${ }^{1}$, Leonardo Draghetti ${ }^{2}$, Sabrina Galiotto ${ }^{2}$, Rebecca L. Orelli ${ }^{1} \&$ Marco Tieghi $^{3}$ \\ ${ }^{1}$ Department of Management, University of Bologna, Italy \\ ${ }^{2}$ Legislative Assembly of the Emilia-Romagna Region, Italy \\ ${ }^{3}$ Department of Sociology and Business Law, University of Bologna, Italy \\ Correspondence: Pietra Paola Amata, Department of Management, University of Bologna. Via Capo di Lucca, 34, \\ 40126 Bologna, Italy. E-mail: pietrapaola.amata2@unibo.it
}

Received: July 13, 2019

doi:10.5539/ijbm.v14n10p185
Accepted: August 15, $2019 \quad$ Online Published: September 9, 2019
URL: https://doi.org/10.5539/ijbm.v14n10p185

\begin{abstract}
The paper sheds light on management control strategies in public administrations, particularly in the case of Legislative Assembly of the Emilia-Romagna Region (AL-RER), to understand reasons, process and effects in the introduction of a management control system. The research makes use of documentary analysis and participatory observation during the years 2015-2019 to reconstruct the motivations, process and results of the introduction of a new management control system. The analysis shows that the introduction of a management control system required different strategies of change and a reorganisation of activities and processes of AL-RER. It also offered an occasion of legitimisation of the AL-RER governance based on the management control results. Furthermore, the analysis shows that the process of introducing a management control system faced obstacles that acted as inhibitors to its introduction. It was possible to overcome the obstacles thanks to an intermediate step, which required a revision of the AL-RER strategies, and a cultural, political, and organisational change. The paper contributes to the advancement of knowledge on the subject of strategies and processes followed by public sector organisations, in particular by regions, in the introduction of management control systems, offering a first contribution concerning obstacles and benefits deriving from the introduction of such systems. The research is also of interest for public sector management, politicians and technicians, as well as for management control specialists, that have to make decisions about the introduction of management control systems.
\end{abstract}

Keywords: Management control system, mangerial changes, public sector management, strategies and processes of change

\section{Introduction}

Over the last decades, the academic literature highlighted the extent, criticalities and benefits of management control tools, explaininig how they unfold their effects in organisational contexts in which they achieve a causal connection with the accounting tools and techniques on the one hand, and the beliefs and values of each organisation on the other. The introduction of control systems therefore acts as a driver of change for the public sector that can lead to innovations in the implementation and use of management control systems.

The purpose of this paper was to carry out an analysis of the motivations, effects and processes underlying the introduction of management control systems, with a special focus on the public sector. The interaction between elements such as culture and values underpins innovation and change, although the final outcome of a change process such as the one under review depends on the accounting tools and techniques developed and used in each organisation.

On the methodological side, our analysis focused on the experience of a regional public body, the Legislative Assembly of Emilia Romagna, Italy, through a tripartite review (documentary analysis, semi-structured interviews and focus groups) that involved project managers in charge of the introduction of management control systems, heads of organisational units and all the employees of selected departments of the organisation. Interviews covered both current and future management control scenarios, with due account taken of the recent accounting harmonisation. As they are based on a case study, the results obtained are not of generic interest, but rather offer some interesting specific insights and food for thought. Our analysis is focused on the process of 
introduction of management control in the PA through an in-depth look at the causes, motivations and processes implemented within the Legislative Assembly of the Emilia-Romagna Region.

This paper is structured as follows. The second section outlines the literature review and the theoretical model for our analysis. In the third section, the methodology followed for the analysis of the AL-RER experience is better illustrated and, in particular, the national context where the regional administration under review operates is described. The fourth section presents and discusses the results of the survey carried out in the light of the three phases of the Lewin's Field Force Analysis model. In the last section, conclusions are drawn and possible future research pathways are identified.

\section{Literature Review and Theoretical Model}

Since the 1980s, but more markedly over the last few decades, there has been a significant transformation of the public sector worldwide, as a result of political, economic, technological and regulatory factors, which have contributed to promoting processes of innovation of public systems with a consequent upgrade of the efficiency of their apparatus, according to the New Public Management (NPM) paradigm (see, inter alia, Hood, 1991; Pollitt \& Boukaert, 2012).

The idea of moving from a Weberian bureaucratic model of the public apparatus to a managerial form of management implemented through a process of 'corporatisation' of the Public Sector with objectives of efficiency, effectiveness and economy, has been a real paradigm shift (Barzelay, 1992; Behn, 2001). One of the central elements of the NPM is the introduction of mechanisms of management control, which has also implied the need for greater awareness on the part of public institutions about concepts such as 'culture of evaluation' and 'control' related to the more general theme of change management in a public context characterised by a constant and rapid change in order to respond with actions tailored each time to the specific requirements of public service users.

To understand the evolution, causes, directions and pathways of such changes in different types of organisations, different approaches can be used (Nahapiet, 1988; Carruthers, 1995; Libby \& Waterhouse, 1996; Dambrin et al., 2007). In an attempt to identify the causes that generate a significant change and its results, some authors have attached great significance to different types of social and relational factors (Abernethy \& Vagnoni, 2004; Bhimani, 1996). Among the various interpretative theories, the Institutional Theory explains the existing links between changes and organisational variables involved, and seeks to identify the mechanisms and effects produced by innovative processes on organisations and stakeholders affected by such processes (Burns \& Scapens, 2000; Covaleski et al., 2003; Tsamenyi et al., 2006; Nor-Aziah \& Scapens, 2007; Arnaboldi \& Azzone, 2010).

In addition to the theories supporting those changes, the analysis of the various reforms that have taken place from time to time in the public administration sector is essential; in particular, our review spans from international reforms (Hood, 1995; Lapsley, 2009; Jones \& Mellett, 2007; Liguori, Sicilia, \& Steccolini, 2012), through reforms which have required regulatory adjustments (Hood \& Peters, 2004; Hood \& Peters, 2004), to national reforms (Hood, 1995; Pollitt \& Boukaert, 2002, 2011; Anessi-Pessina \& Steccolini, 2005). The initiation of a process of change therefore requires taking into account the potential final outcomes of the control system as well as, more importantly, all the impacts that the control system produces in the organisation (Connolly \& Hyndman, 2006; Liguori \& Steccolini, 2012; Cardoni, 2018) and that are affected by the rules, values, interests and behaviours of the organisation itself and of society (Burns \& Scapens, 2000; Liguori \& Steccolini, 2012). Appropriate instruments and related accounting techniques developed and used will then validate the soundness of the final result of the change process (Burns \& Scapens, 2000; Lounsbury, 2001; Liguori \& Steccolini, 2012; Pavan \& D’Onza, 2013; Maraghini, 2018; Mancini, 2018).

In order to give substance to causes, limiting factors, methods and effects that have allowed the initiation of a change process, and therefore the introduction of management control tools suited to meet internal and external pressures (Wickramasinghe \& Alawattage, 2007, p. 18), we thought it appropriate, for the purposes hereof, to adopt the perspective proposed by Lewin $(1951,1958)$, which focuses on the dynamics of planned change through the analysis of forces driving the process through actions of stimulus and support on the one hand, and of opposing inhibitory forces which tend to hinder the advancement of change on the other.

Lewin's Field Force Analysis model is designed to strengthen the factors that stimulate and support the process of change so as to reduce and even completely overcome the inhibitory forces that tend to hinder it, without overlooking the fact that one of the crucial variables of the entire process is the awareness of the attitude of people involved. According to Lewin (1958), achieving change means being able to act (i.e. to 'change') at all levels, i.e. individual, interpersonal and organisational (Sharma, 2007). In order to achieve an organisational 
change, people working in an organisation must adopt behaviours, values and skills that are consistent with the objective of the organisational change itself. The reporting systems and their operational mechanisms therefore also need to be modified.

In a nutshell, Lewin's three-phase model (1958) suggests the recurrence of a cycle (Mecca, 2004), i.e. the process starts through the 'unfreezing' of a given situation as a result of pressure inducing change. This implies the search for new conditions of balance; when this balance is achieved, the situation tends to refreeze again until new events cause the restart of the process.

The first phase of the Lewin's model $(1951,1958)$ is therefore unfreezing/motivation, i.e. breaking down the status quo. The correct preparation of unfreezing is a fundamental requirement of the process (Stevens, 2013). Amenability to change encourages people to be ready to accept it and therefore interrupt the status quo, leading them to internalise the need to change (Dixon et al., 2006). The need to change emerges as a result. The unfreezing and motivation phases are considered to be identical, i.e. when the status quo is affected by a disruptive force such as to encourage people to change their behaviour (Mecca, 2004). Balance is altered when, in addition to the introduction of an 'external' force pressing for change, a motivation for change is created (McShane \& Von Glinow, 2001; Schein, 1996). During the unfreezing phase people constitutes fundamental supporters of change (Armenakis \& Harris, 2002, p. 169), since they are active elements in trying to solve problems and are motivated to promote change (Mecca, 2004, p. 2). The unfreezing phase can be facilitated through the adoption of motivation support actions, that is change-preparation and confidence-building initiatives (Robbins et al., 2003). The unfreezing phase creates the necessary motivational tension, but does not determine or predict the direction of change (Schein, 1996, p. 62), which necessary requires the start of a subsequent transition phase.

Once the unfreezing phase has been completed, the transition/management phase begins. According to Bridges and Mitchell (2000), the effect of each change is determined by the transition dynamics that define its success or possible causes of failure. In this phase, the condition is characterised by fragility and instability, with the desired new state of equilibrium still has to be achieved (Mecca, 2004). The success of the change effort can only be achieved, through a cultural and structural change, and the with new values and processes (Burns, 1996) offered by this transition phase. When change enters the second phase, it is necessary that the new modes of operation are accepted by people, because, to support change, these changes must be accepted (Dixon et al., 2006; Senior, 2002; Werner, 2002). In addition, the transition process is inherent in the manner this transition to change is managed. In this regard, Kotter and Schlesinger $(2008$, p. 3) believe that even changes that are considered positive or rational involve a certain degree of uncertainty. Key people who drive change will need to pay particular attention to offer opportunities for reinforcement and to persuade people to indulge in the benefits of change (Kritsonis, 2004; Lewin, 1947; McKee et al., 1998).

The third and final phase of Lewin's model is that of refreezing/institutionalising. It is intended as a process through which changes become effective and stabilise, with people applying new approaches and new forms of understanding, making use of new working methods in this daily activity. The refreezing phase therefore institutionalises and internalises a change, which thus becomes the new natural and shared mode of action (Dixon et al., 2006).The effects of change will be aligned with individual personalities. The refreezing phase is intended to bring about lasting changes in the culture, policies and practices implemented at the organisational level (Kanter \& Stein, 1992), to put a stop to the change process (Mecca, 2004). Actions of positive reinforcement towards new organisational configurations can be achieved through the adoption of formal and informal mechanisms to support the change (Robbins, 2003).

Lewin's three-phase model clearly shows that in order to achieve a lasting change, the combination of forces must therefore shift in favour of those that induce change by overcoming the resistance of forces that oppose it (Robbins, 2003). A plan of action and management of the first two phases of unfreezing and transition is fundamental to successfully carry out the refreezing phase (Mecca, 2004).

Outlining the key features of Lewin's model helps to understand how it can be used to analyse the specific responses of the local public administration to a change in the accounting practices, such as the introduction of new forms of management control. Lewin's model is therefore instrumental in analysing and understanding the nature and intensity of internal forces within local public authorities influencing a change brought about by the adoption, implementation and actual use of management control systems, and how this produces a new daily accounting practice in each specific organisation.

\section{Method and Context}

The purpose of this paper is to analyse the implications of adopting a management control system through the 
experience of the AL-RER. The Lewin's model proposed here is designed to understand the forces of internal change that emerged at the time of introducing a management control system based on the AL-RER activities.

For the purpose hereof, the use of case analysis, which is focused on dynamics in a specific situation (Eisenhardt, 1989), helps explain phenomena even when the boundaries between internal and external phenomena are not clearly evident and when different types of sources are used (Yin, 2013: 23). In such circumstances, the use of cases also makes it possible to identify a concrete causal relationship between the phenomena being analysed (Bennett ad Elman, 2006).

Let us now move on to the characteristics of the Italian public institution under review, AL-RER. Before describing its characteristics, it might be helpful to analyse the management control choices in the context where they have developed, i.e. the Italian public administration, with special reference to the introduction and implementation of management control systems in the public sector. To investigate the forces underlying the implementation of management control in the PA, a public body that had not yet introduced management control was chosen. In 2015, the only regional body that was preparing to structure a new and initial management control system was the AL-RER, the decision was made to choose the AL-RER as a case study since this condition was satisfied.

The use of the AL-RER case can be helpful for a number of purposes and offers working hypotheses whose analysis can facilitate the understanding of other cases (Lincoln \& Guba, 1985). It helps to compare similarities between the investigated case and other organizations that are in similar situations. With this methodology, it recurs the limits of generalizations (Yin, 2013).

For the development of the analysis, any possible information was collected in terms of programming, control and reporting documents existing in the AL-RER. Then, we proceeded to a semi-structured interview, organised in accordance with the approach of the Lewin's model. In the surveys carried out in each public body, sources of documentary information were cross checked with the contents of interviews in order to ensure accuracy and internal consistency (Eisenhardt \& Graebner, 2007).

Focus groups and semi-structured interviews were carried out with all AL-RER managers in the period December 2015-June 2018, each with different responsibilities and roles within the AL-RER. The longitudinal analysis allowed us to consider all phases of change at the time they occurred and also later in time.

\subsection{The Italian Context and the Legislative Assembly - Emilia-Romagna Region}

This analysis has been developed in relation to the context of the Consiglio Regionale della Regione Emilia-Romagna, which the Regional Statutes call Assemblea Legislativa. AL-RER's Mission includes the policymaking and administration of the Emilia Romagna Region, in addition to its law-making functions, i.e. the power to create laws within its scope of responsibilities as defined by the Italian Constitution. The AL-RER has its own rules of procedure, budget and staff, which are distinct and separate from those of the Giunta regionale (Regional Cabinet) in respect of which it acts as an instrumental body. To better understand the results of our study, a short overview should be made of the national reference context.

At national level, the beginning of the renewal process by Legislative Decree 118/2011 and the consequent application, from 2016, of a new harmonised accounting system has fostered the start of a new management control cycle in public administration. In particular, the administrative sector reform started with Law 109/2009 (for the central government and public sector bodies) and Law 42/2009 (for regions and local authorities). The two laws caused a quantum shift towards the harmonisation of the public sector accounts achieved through the creation of a single accounting system architecture and the adoption of a unique set of principles, so much so that measurement and recognition methods were standardised with a consequent, generalised innovation not only in accounting, budgeting and financial reporting systems, but also in the use of local governments' management control systems. In confirmation of the above, Article 2 of Legislative Decree 118/2011, which implements the delegation of legislative powers to the government pursuant to Law 42/2009, states that: "The regions and local authorities referenced in Article 2 of Legislative Decree no. 267 of 18 August 2000 shall adopt financial accounts disclosed by an appropriate set of financial statements, where operating results, assets and liabilities and cash flows are measured and recognised in accordance with standardised methods".

Although there have been different approaches to theme of PA control in various studies, there has been a general tendency to build a network of internal controls to verify the extent to which the administrative system of an institution is able to pursue its management objectives. This ability can then be measured also following the Corte dei conti indications, the Italian external organization for pulic sector control activities (Corte dei Conti, 2017, p. 29), by building suitable indicators crossing data with each other and verifying a full set of parameters: 
adequacy of programming, level of implementation of the programme in terms of performance, efficiency and cost-effectiveness, quality and quantity of services delivered, and ability of the organisation to achieve the objectives sought. The values of these indicators should help the institution fine-tune its management by implementing appropriate corrective measures and remedying the criticalities that have emerged while ensuring that financial balance is achieved and the principles of sound management are observed.

The AL-RER, in particular, started a 'modernisation' process with Regional Law 43/2001, dedicated to internal controls, which was later completed by a set of subsequent legislative acts for the development of a control system suited to its structure. In particular, by the Regional Cabinet Resolution (DGR) no. 468/2017 entitled 'Il Sistema dei controlli interni nella Regione Emilia-Romagna' (System of Internal Controls in the Emilia-Romagna Region) (as well as Resolution 87/2017 of the AL-RER Bureau), a system of internal regional controls was formalised and new forms of controls were introduced, such as ex-post administrative regularity control, strategic control and management control.

The path followed reflects the provisions of the Consolidated Act on the Regulatory System of Local Authorities (TUEL), Legislative Decree 267/2000, Article 147, para. 2, which governs precisely management controls. Moreover, Legislative Decree 286/1999, which implements Law 59/1997 (Bassanini Law), introduces the corporate concept of 'sound management', giving concrete form to concepts such as performance, efficiency and cost-effectiveness through the evaluation and measurement of activities carried out by an individual public authority. The subsequent Decree-Law 174/2012 reinforces the obligations of internal controls (already provided for by Article 147 of the TUEL) by introducing further control areas to reflect the size of the public authority. With special regard to management control, Legislative Decree 150/2009 introduces specific provisions governing performance management by defining the bodies in charge of performance monitoring with a view to improving the PA quality of service and by setting up a performance measurement and evaluation system aimed at favouring the growth of professional skills through the recognition of merit and the provision of awards for the results pursued by individuals and organisational units, in a context of equal opportunities of rights and duties, transparency of the results of the same institution and resources used to pursue them. The same Legislative Decree 150/2009, as amended by Legislative Decree 74/2017, identifies four bodies responsible for the process of measuring and evaluating organisational and individual performance of each public authority: the Dipartimento di Funzione Pubblica (Civil Service Department), the OIVs (Independent Performance Evaluation Bodies), the Organo di indirizzo politico ed amministrativo (Policymaking and Administrative Body) of each public authority, and the Managers of each public authority.

Finally, before discussing the results of the study, it should be set forth that, for the exercise of its functions as specified in its Statutes, the AL-RER is organised into two Structures: an Ordinary Administrative Structure and a Special Policymaking Structure. The Special Structure is bound by an exclusive delegation of powers from and acts on behalf of Institutional Bodies and Political Groups. It includes: the Presidenza dell'Assemblea Legislativa (Speakership of the Legislative Assembly), the Consiglieri (Councillors), the Ufficio di Presidenza (Bureau), the Gruppi assembleari (Assembly Groups), and the Commissioni assembleari (Assembly Committees). The Ordinary Structure carries out all the activities of technical-administrative nature provided for in the relative programming documents (such as the PDA or 'Activity Plan'). The current organizational structure includes three Servizi i.e. Departments (Legislative Affairs \& Coordination of Assembly Committees, Operation \& Management, and Citizens' Rights) and a Direzione Generale - i.e. Directorate-General - which has a cross-functional role that links the above Departments together and manages all instruments related to strategic planning, programming, coordination, monitoring and evaluation; in addition, in its exercise of managing duties, the Directorate-General has the task of ensuring compliance with the principle of collaboration between the policymaking and the administrative functions in order to pursue the fundamental objective of favouring sound administration and the highest possible efficiency of administrative actions, as provided for in the Italian Constitution. The Directorate-General is also responsible for the coordination of organisational innovation projects such as the design and implementation of change management actions.

\section{Management Control in the AL-RER: Results and Discussion}

The theoretical framework of Lewin's Field Force Analysis is instrumental in interpreting the dynamics of change in the AL-RER. With reference to the first phase, in particular, the pressures that triggered a shift away from the status quo, i.e. the motivation/unfreezing dynamics for change, can be easily identified.

The first and, perhaps, the most important motivation was the changed external context. In particular, brisk lawmaking at both national (Pavan \& D’Onza, 2013, p. 5; Gori \& Fissi, 2011) and international level has required continuous adaptation in management policies so as achieve uniformity and comparability between 
accounting systems and, therefore, controlling systems (Marchi, 2011).

Such external pressure was accompanied by an internal motivation expressed by the Regional Cabinet at the beginning of its mandate. More specifically, with regard to the 2015 budget and in conjunction with the start of the new government term, the Cabinet chose to bring forward the preparation of the Regional Document on Economy and Finance (DEFR) - although this was only at trial level - in order to pursue a goal of transparency for the benefit of the Legislative Assembly as well as citizens, businesses and the regional territory as a whole. The preparation of the DEFR brought forward to 2015 helped translate the political commitments planned for the five-year period into objectives, as early as in the first year of legislature, in line with the Regional Government's Programme for Simplification and Efficiency. Prospectively, this approach is intended to lay down the foundations for the exercise of the duty of assessing the achievement of strategic objectives and the impacts of change and development produced on the territory and the community. Indeed, Legislative Decree 118/2011 closely links this duty of assessment to the DEFR itself. Therefore, the desire to translate the regulatory framework into operational objectives is strongly political in nature, since among the political priorities set by the Directorate-General of the Legislative Assembly is the need to build a system of integrated strategic planning that includes the following three macro strategic objectives for the 2016-2018 period: harmonisation of strategic planning and management control documents; reorganisation and evaluation systems; and finally organisational efficiency and cost containment. The above external and internal motivations acted as a disruptive force (Mecca, 2004) although regulatory actions triggered by motivations did not suffice to alter the status quo; rather, the role of people that took the lead in this face of change (Armenakis \& Harris, 2002) was decisive.

Technically speaking, the first approach to building an integrated strategic planning system required a discussion with experts from outside the legislative assembly. More specifically, AL-RER's Directorate-General took account of the Assembly's organisational structure, functioning and general setup and identified the need to introduce instruments that would ensure the knowledge, analysis and rational management of consumed resources and of costs arising from the provision of services to the regional community, in order to avoid wasting such resources, which had been acquired with the money of the same community. AL-RER's Directorate therefore expressed a third, consequential motivation for a shift away from the status quo.

In chronological order, the first phase of motivation/unfreezing started in December 2015, with the beginning of the 10th Legislature of the regional government when, following the guidelines issued by the Bureau (which fulfils duties of political and administrative guidance), the political priorities defined by the new government were translated into strategic objectives including, but not limited to, the efficiency and effectiveness of the administrative action to be achieved, inter alia, through the control of expenditure. The Legislative Assembly, and in particular the Bureau, therefore gave a first political start to the process of analysing the activities of the institution to determine the strategic and operational objectives in the ordinary and special structure of the Assembly in a more effective and efficient way.

In addition to this first political motivation, another motivation was particularly felt in 2015 , i.e. the need to more promptly meet the demands of citizens by overseeing factors such as the swiftness, efficiency and effectiveness of activities designed to meet those demands. With that in mind, a clear assessment had to be made of choices with regard to forms of management of services to be provided, organisational setup of the AL-RER to that end, and a regular, accurate measurement of customer satisfaction with those services.

In order to more properly evaluate the margins for change that the transition to a new organisational setup could entail, AL-RER's Directorate-General prepared a reorganisation and simplification proposal that took on board the regional guidelines (as outlined in the DEFR), which would guide and support the entire process of change. These guidelines included strategic planning, programming, management control, evaluation system and performance plan, quality management system, customer satisfaction analysis, innovation and dematerialisation. To support the idea of integrating the control mechanisms into the entire AL-RER programming and control process, the primary objective of the reorganisation design was the progressive integration between strategic, economic and financial programming cycle on the one hand and the performance cycle on the other.

The Manager in charge of the process was the Director-General of AL-RER, who jointly with the Managers of the other Servizi (Departments) took the lead and moved forward towards a profound turnaround in the institution's organisation and control mechanisms. This phase involved both an information campaign and a targeted training programme in forms of management control and in methods designed to overcome limits deriving from the previous absence of such control and contributed to building an attitude of trust designed to reinforce the change (Robbins et al., 2003). To disseminate such information and training initiatives to the entire personnel of the AL-RER, specific coaches were hired who, after an appropriate training, assisted and 
contributed to clarify the doubts and/or uncertainties expressed by the AL-RER's employees with regard to any issues and tense situations that could arise from a possible future change. The proposal was ultimately shared with the trade unions and all employees through targeted meetings.

The second transition/management phase started with the effective reorganisation of AL-RER's responsibilities and activities following the Bureau's resolution no. 102/2015 entitled "Linee di indirizzo in materia di organizzazione e gestione del personale" (Guidelines for personnel organisation and management) and implementing the reorganisation proposal by redesigning the functional setup of AL-RER's Directorate-General as well as of the Departments of the Legislative Assembly. This document also proposed a possible solution to some outstanding issues, in particular the separation between politics and administration, the issue of controls and the distribution of responsibilities. The need to drive behaviours in the direction taken also implied an assessment of the critical points, which, when not properly addressed, risked weakening, if not eliminating, the positive effects of the organisational turnaround. This first step 'translated' a political priority into a strategic objective and, consequently, into operational actions and also contributed to taking on board new values and processes (Burns, 1996).

In a subsequent phase, the AL-RER Manager Coordination Unit set out the path to be taken for the implementation of the identified objectives. In particular, with regard to control, the initial decision was to launch an experimental process of organisational change and to set up a management control system starting from the Ordinary Structure, as the one better suited to the process for its static nature compared to the Special Structure, whose dynamism was linked to the Legislature in office. The reorganisation proposal also defined a new structural architecture for the AL-RER based on three areas of activities, i.e. Legislative Activities, Citizens' Rights and Operation \& Management. This reorganisation was consistent with the dynamics already identified in the literature in order to find new ways to perform individual tasks (Dixton et al., 2006). In particular, at this stage, the Directorate-General was entrusted with additional functions of control and ownership of performance evaluation tools in addition to its previous planning, programming and coordination tasks. In this way, the Directorate has become a body linking together the positions of all functional units and persons concerned with change, with the ability to offer opportunities for reinforcement and persuade people to indulge in the benefits of change (Kritsonis, 2005).

In the previous motivation/unfreezing phase, a positive assessment had been made with regard to the implementation of an AL-RER management control system in a 'test' version, i.e. a management control system for activities/processes (Activity-Based Costing - $\mathrm{ABC}$ ) to be relied upon for subsequent change decisions (Activity-Based Management - ABM or ABCM).

From an operational standpoint, the strategy of involving the entire organisation implied the presentation of the various phases of the project implementation in a meeting of the AL-RER's Manager Coordination Unit under the leadership of the Directorate and, the subsequent illustration of the project through plenary meetings with the organisational units involved. In this context, it should be noted that constant attention was paid to all the interests at stake, by means of updates on the progress of the process, which also involved the trade unions. The commencement of the transition test phase only concerned a few of the organisational units selected by AL-RER's Director-General. Since all the activities carried out by each Department are from time to time codified and described in an annual Programme of Activities (PdA), the PdA 2016 was the information base used for measuring the activities. The selection criterion adopted for units to be analysed also relied on the mapping of processes underlying the activities. However, at the start of this test phase, such mapping still had to be completed, which was one of the critical points that emerged during this phase. In any case, this exercise was instrumental in re-mapping the AL-RER activities in the light of the new organisational setup as well as the actual activities carried out by those who actively participated in the collection and verification of information concerning them. In practice, the personnel cost drivers were measured and analysed by handing out forms for assessing the activities carried out and the relevant time spent on such activities by the interviewed personnel. In addition to the personnel cost drivers, the survey helped identify possible improvements. All AL-RER employees took part directly in this first phase of activity-specific survey, and all operational processes that involved them were checked.

The second part of the activity-based management control test would have required non-personnel costing. However, the information and accounting system on which this costing exercise relied proved incapable of meeting the analytical information requirements in the short term. Such lack ultimately caused a setback in the implementation of the ABC within the AL-RER and could have effectively inhibited the entire process of change (Mecca, 2004). 
In this context, not to frustrate the early fruitful efforts of introducing change in the logic of activities and processes, the Directorate-General, with the assistance of AL-RER's Programming and Control Area, which had been created for this purpose, decided to add an overlapping management control system organised by responsibility centres to the existing management control system dedicated to the $\mathrm{ABC}$, at least for the part relating to personnel costs. The result was a hybrid management control architecture combining $\mathrm{ABC}$ and responsibility centres. In this architecture, each AL-RER Department and the Directorate-General itself were identified as responsibility centres in charge of objectives, resources and management results in terms of efficiency and effectiveness. This new step implied further levels of information sharing where the Directorate-General, assisted by the Programming and Control Area, acted again as an agent of change (Dixon et al., 2006).

The third and last phase of Lewin's model is the refreezing/institutionalising phase. The Directorate-General and, subsequently, the Programming and Control Area stood out for their ability to provide positive reinforcements to the institutionalisation of management control through the hybrid solution of $\mathrm{ABC} /$ responsibility centres. Indeed, the information obstacles encountered could have impaired the entire architecture of the change already achieved through the phases of motivation and transition. Through these efforts, instead, the management control system was successfully implemented and extended to all AL-RER Departments and Areas in the financial years 2016 and 2017 , thus putting an end to the testing phase.

Moreover, the upgrade to a new harmonised accounting system, which was introduced by Legislative Decree 118/2011 and came into operation in 2015 for the AL-RER, facilitated the contracting out of a management application module (combining operating results and financial position and performance in an integrated chart of accounts) to a specialised provider. The forthcoming release of that module will allow for the first time the measurement and analysis of all types of costs.

The introduction of management control in AL-RER offers the opportunity to unfold some managerial implications. In strategic terms, the opportunity to draft summary reports based on the new management control system focusing on the operating costs of individual operating units, and the further opportunity to match achieved results to expected results and initiate possible expenditure containment, rationalisation and optimisation actions will enable AL-RER's Director-General to define interventions over a multiannual time horizon, with annual details, for the definition of objectives, areas and methods designed to optimise management and achieve, at the same time, a greater degree of legitimacy based on a more transparent reporting mechanism for AL-RER's processes and results to the benefit of citizens/users (Kanter \& Stein, 1992). In managerial terms, the management control activities implemented offered the opportunity to revise previous strategies with new tools of analysis that, in turn, gave options to expenditure constraints faced by AL-RER.

Also, on the managerial perspective, the introduction of conditions for management control (shared throughout the organisation) has created an organisational culture of control which goes hand in hand with a) the new organisational setup of the institution, b) its ongoing acquisition of knowledge and skills required to achieve technical, organisational, procedural and training compliance and ultimately overcome the obstacles encountered, and c) its partnership and collaboration with the entire regional and independent professional network (Robbins, 2003), thus enabling the AL-RER to be the first regional institution capable of institutionalising a management control system for activities and processes. The three elements can be seen as a roadmap to be followed by managers willing to foster the introduction of management control and its positive effects on the organization.

\section{Conclusions}

Our research was aimed at understanding the motivation, process and effects of introducing a management control system in public administration and was based on the analysis of the experience of a regional public body, the AL-RER, in the period 2015-2019.

The analysis - which relies on the theoretical framework offered by Lewin's Field Force Analysis - shows that the introduction of a management control system has required different and strong external and internal motivations for change, an extensive activity of general input and support to understand management control needs and a first test proposal following training, information and consultation processes extended to all AL-RER employees, to then start reorganising activities and processes and finally introduce a hybrid form of management control whose ultimate purpose is to legitimise AL-RER's governance for the very fact that its decisions are for the first time also based on the results of management control.

In addition, the analysis revealed that the process of introducing a management control system has encountered unexpected obstacles which could have inhibited such introduction (i.e. the unavailability of comprehensive analytical IT tools necessary for management control). These obstacles were overcome by using an intermediate 
step, which involved a revision of AL-RER's strategies, after which the management control system could go live as a result of a cultural - and not merely political and organisational - change supported by the implementation of accounting and control techniques. Such a breakthrough would have been impossible if the AL-RER had not had a pre-existing culture of control; indeed, such element prevented the entire system from being frustrated and halted by the inhibitory forces that inevitably emerged.

This paper contributes to the advancement of knowledge on the subject of strategic and operational choices made by local authorities, and regions in particular, in the introduction of management control systems and offers an early insight into the obstacles and benefits arising from the introduction of such systems. Our contribution might be of interest for the senior politicians and technical managers of public bodies who are required to make decisions on the management control system to be introduced, as well as for specialists in management control because it offers clear indications about possible unexpected obstacles to the introduction of management control as well as factual indications to overcome them.

\section{References}

Abernethy, M. A., \& Vagnoni, E. (2004). Power, organization design and managerial behavior. Accounting, Organizations and Society, 29(3), 207-225. https://doi.org/10.1016/S0361-3682(03)00049-7.

Anessi-Pessina, E., \& Steccolini, I. (2005) Evolutions and Limits of New Public Management-Inspired Budgeting Practices in Italian Local Governments. Public Budgeting \& Finance, 25(2), 1-14. https://doi.org/10.1111/j.0275-1100.2005.00358.

Armenakis, A., \& Harris, S. (2002). Crafting a change message to create transformational readiness. Journal of Organizational Change Management, 15(2), 169-183. https://doi.org/10.1108/09534810210423080.

Arnaboldi, M., \& Azzone, G. (2010). Constructing Performance Measurement in the Public Sector. Critical Perspectives on Accounting, 21(4), 266-282. https://doi:10.1016/j.cpa.2010.01.016

Barzelay, M. (1992). Breaking through bureaucracy: A new vision for managing in government. Univ. of California Press.

Behn, R. D. (2001). Rethinking democratic accountability. Brookings Institution Press.

Bennett, A., \& Elman, C. (2006). Qualitative Research: Recent Developments in Case Study Methods. Annual Review of Political Science, 9, 455-476. https://doi.org/10.1146/annurev.polisci.8.082103.104918

Bergamin, B. M. (1983). Il controllo di gestione nelle imprese italiane. Milan: Etas Libri.

Bhimani, A. (1996). Management accounting: European perspectives. Oxford: Oxford University Press.

Bridges, W., \& Mitchell, S. (2000). Leading transition: A new model for change. Leader to Leader, 16(3), 30-6.

Burns, J., \& Scapens, R. W. (2000). Conceptualizing management accounting change: An institutional framework. Management Accounting Research, 11(1), 3-25. https://doi.org/10.1006/mare.1999.0119

Cardoni, A. (2018). Le sfide evolutive del Management Control tra relazioni Strategiche, innovazione e discontinuità: a knowledge transfer matter? Management Control, (1), 5-15. https://doi.org/10.3280/MACO2018-001001

Carruthers, B. (1995). Accounting, ambiguity, and the new institutionalism. Accounting, Organizations and Society, 20(4), 313-328. https://doi.org/10.1016/0361-3682(95)96795-6

Connolly, C., \& Hyndman, N. (2006). The actual implementation of accruals accounting: Caveats from a case within the UK public sector. Accounting, Auditing \& Accountability Journal, 19(2), 272-290. https://doi.org/10.1108/09513570610656123

Corte dei Conti - Sezioni riunite in sede di controllo. (2017). Programmazione dei controlli e delle analisi della Corte dei Conti per il 2018, Delibera n. 12/2017/SSRRCO/INPR.

Covaleski, M. A., Evans, J. H., Luft, J. L., \& Shields, M. D. (2003). Budgeting Research Three Theoretical Perspectives and Criteria for Selective Integration. Journal of Management Accounting Research, 15, 3-49. https://doi.org/10.2308/jmar.2003.15.1.3

Dambrin, C., Lambert, C., \& Sponem, S. (2007). Control and Change-Analysing the process of institutionalization. Management Accounting Research, 18, 172-208. https://doi.org/10.1016/j.mar.2007.02.003

Dixon, R., Ritchie, J., \& Siwale, J. (2006). Microfinance: accountability from the grassroots. Accounting, Auditing \& Accountability Journal, 19(3), 405-427. https://doi.org/10.1108/09513570610670352 
Eisenhardt, K. M. (1989). Building Theories from Case Study Research. The Academy of Management Review 14(4). https://doi.org/10.5465/amr.1989.4308385

Eisenhardt, K. M., \& Graebner, M. E. (2007). Theory building from cases: Opportunities and challenges. Academy of Management Journal, 50(1), 25-32. https://doi.org/10.5465/amj.2007.24160888

Farneti, G. (2005). Gestione e contabilità dell'ente locale. Rimini: Maggioli.

Gori, E., \& Fissi, S. (2011). La contabilità analitica: presupposto necessario e sufficiente per la determinazione degli standar di costo negli enti locali. Management Control, (2), 85-104. https://doi.org/10.3280/MACO2011-002005

Hood, C. (1995). New Public Management' in the 1980's: Variations on a theme. Accounting Organizations and Society, (2-3), 93-109. https://doi.org/10.1016/0361-3682(93)E0001-W

Hood, C., \& Peters, G. (2004). The middle aging of new public management: into the age of paradox? Journal of Public Administration Research and Theory, 267-282. https://10.1093/jopart/muh019

Jones M. J., \& Mellett, H. J. (2007). Determinants of changes in accounting practices: Accounting and the UK Health Service. Critical Perspectives on Accounting, 18, 91-121. https://doi.org/10.1016/j.cpa.2005.05.003

Kanter, R. M., Stein, B. A., \& Jick, T. D. (1992). The Challenge of Organisational Change. The Free Press, New York, NY.

Kotter, J. P., \& Schlesinger, L. A. (2008). Choosing Strategies for Change. Harvard Business Review, 86(7-8).

Kritsonis, A. (2004). Leadership In Organizations: National Implications. International Journal of Management, Business, and Administration, 7(1).

Lapsley, I. (2009). New Public Management: The Cruellest Invention of the Human Spirit? Abacus, 45(1), 1-21. https://doi.org/10.1111/j.1467-6281.2009.00275

Lewin, K. (1947). Frontiers in group dynamics: concept, method and reality in social science; social equilibria and social change. Human relations, (1), 5-40. https://doi.org/10.1177/001872674700100103

Lewin, K. (1951). Field Theory in Social Science. Selected Theoretical Papers.

Lewin, K. (1958). Group decision and social change. In Maccoby, E. E., Newcomb, T. M. \& Hartley, E. L. (Eds.), Readings in Social Psychology (pp. 197-211). Holt, Rinehart and Winston, New York,

Libby, T., \& Waterhouse, J. H. (1996). Predicting change in management accounting systems. Journal of management accounting research, 8, 137.

Liguori, M., Sicilia, M., \& Steccolini, I. (2012). Some Like it Non-Financial... Politicians' and managers' views on the importance of performance information. Public Management Review, 14(7), 903-922. https://doi.org/10.1080/14719037.2011.650054

Lincoln, Y. S., \& Guba, E. G. (1985), Naturalistic Inquiry. London: Sage.

Mancini, D. (2018). Evoluzione e prospettive dei sistemi di informazione e controllo. Management Control, (Suppl), 2, 5-14. https://doi.org/10.3280/MACO2018-SU2001

Maraghini, M. P. (2018). Management Control: il "gattopardo" per il governo aziendale. Management Control, 3, 5-11. https://doi.org/10.3280/MACO2018-003001

Marchi, L. (2011). Integrazione pubblico-privato su metodologie e strumenti di controllo gestionale. Management Control, 2, 5-8. doi: 10.3280/MACO2011-002001

McKee, M., Aiken, L., Rafferty, A. M., \& Sochalski, J. (1998). Organisational change and quality of health care: an evolving international agenda. Quality in health care: QHC, 7(1), 37-61. https://doi.org/10.1136/qshc.7.1.37

McShane, S. L., \& Von Glinow, M. A. (2000). Organizational behavior. Boston: Irwin McGraw-Hill.

Mecca, T. V. (2004). Basic concepts of organisational change for administrative leaders. Lisle, IL: Pacific Crest.

Mussari, R. (2011). Economia delle amministrazioni pubbliche. Milan: McGraw-Hill.

Nahapiet, J. E. (1988). The rhetoric and reality of an accounting change: A study of resource allocation in the NHS. Accounting, Organizations and Society, 13, 333-358. https://doi.org/10.1016/0361-3682(88)90009-8

Nor-Aziah, A., \& Scapens, R. W. (2007). Corporatisation and accounting change: The role of accounting and accountants in a Malaysian public utility. Management Accounting Research, 18(2), 209-247. 
https://doi.org/10.1016/j.mar.2007.03.003

Orelli, R. L., \& Visani, F. (2004). Strumenti di analisi e gestione dei costi: Lo stato dell'arte nei Comuni italiani. Azienda Pubblica, 17(4), 587-606.

Pavan, A., \& D’Onza, G.(2013). Innovare I sistemi di controllo e di governance per gestire il cambiamento. Management Control, 2, 5-7. https://doi.org/10.3280/MACO2013-002001

Pollitt, C., \& Bouckaert, G. (2012). Public Management Reform: A Comparative Analysis-New Public Management, Governance, e the Neo-Weberian State. Oxford: Second edition, Oxford University press.

Schein, E. (1996). Culture: The missing concept in organization studies. Administrative Science Quarterly, 41(2), 229-240. https://doi.org/10.2307/2393715

Senior, B. (2002). Organisational Change. London, Prentice Hall.

Stevens, B. (2013). How ethical are US business executives? A study of perceptions. Journal of Business Ethics 117(2), 361-369. https://doi.org/10.1007/s10551-012-1510-4

Tsamenyi, M., Cullen, J., \& González, J. (2006). Changes in Accounting e Financial Information System in a Spanish Electricity Company: A New Institutional Theory Analysis. Management Accounting Research, 17(4), 409-432. https://doi.org/10.1016/j.mar.2006.02.002

Werner, S. (2002). Recent developments in international management research: A review of 20 top management journals. Journal of Management, 28(3), 277-305. https://doi.org/10.1016/S0149-2063(02)00129-0

Wickramasinghe, D., \& Alawattage, C. (2007). Management Accounting Change: Approaches e Perspectives. Oxon: Routledge.

Yin, R. K. (1913). Case study research: design e methods. Newbury Park, Sage.

\section{Copyrights}

Copyright for this article is retained by the author(s), with first publication rights granted to the journal.

This is an open-access article distributed under the terms and conditions of the Creative Commons Attribution license (http://creativecommons.org/licenses/by/4.0/). 